\title{
UTILIZAÇÃO DO TRIBÔMETRO PARA ESTUDO E AVALIAÇÃO DE DIFERENTES TIPOS DE MODIFICADORES DE ATRITO
}

\author{
Cíntia de Holleben ${ }^{1}$, Hugo Cavalcante Peixoto ${ }^{1}$, Roberta de Almeida Carvalho ${ }^{1}$ \\ ${ }^{1}$ Iconic Lubrificantes S.A. \\ E-mails: cintia.holleben@iconiclubrificantes.com.br, \\ hugo.peixoto@iconiclubrificantes.com.br, \\ roberta.carvalho@iconiclubrificantes.com.br
}

\section{RESUMO}

Aditivos modificadores de atrito são empregados atualmente em formulações com o propósito de melhorar o desempenho final do lubrificante, alterando o atrito entre as superfícies móveis em contato. Diante disso, o presente trabalho avaliou o coeficiente de atrito de diferentes formulações, para as quais foram selecionados três óleos básicos de diferentes origens e aditivos modificadores de atrito com naturezas químicas distintas. A metodologia aplicada considerou o uso de um Tribômetro e as condições de carga e temperatura de todos os testes foram mantidas constantes. Para cada teste foi obtida uma curva de Stribeck, nas quais verificou-se que as diferenças químicas dos aditivos e básicos avaliados interferem diretamente no coeficiente de atrito e na sinergia entre eles. Os aditivos modificadores de atrito atuam na superfície metálica e por isso, podem competir com outros tipos de aditivos que também atuam na superfície, tais como aditivos antidesgaste e extrema pressão. As análises prévias realizadas com auxílio do Tribômetro podem auxiliar na escolha das melhores opções a serem empregadas na formulação e desenvolvimento de novos lubrificantes.

Palavras-chave: tribologia, aditivo modificador de atrito, Curva de Stribeck.

\section{INTRODUÇÃO}

Controlar a fricção entre superfícies móveis em contato é fundamental para maximizar a eficiência de operação, a eficiência energética do combustível e o tempo de vida dos equipamentos[1]. Neste sentido, o lubrificante desempenha papel importante para a redução do atrito, garantindo a manutenção da película lubrificante.

A tendência dos novos óleos para aplicação automotiva é apresentar viscosidades cada vez mais baixas, com alta resistência ao desgaste e boa 
estabilidade oxidativa [2]. Os requisitos de eficiência energética e redução das emissões regulamentados e exigidos por diversos órgãos internacionais atuam como principais motivadores para o desenvolvimento de lubrificantes com desempenho diferenciado que atendam estes requisitos. Neste cenário, aditivos do tipo modificadores de atrito (friction modifiers) desempenham papel fundamental para que o lubrificante desenvolvido atinja plenamente todos os requisitos de eficiência energética [1]. A atuação destes aditivos no lubrificante pode ser melhor compreendida através da análise da curva de Stribeck.

A curva de Stribeck é uma forma gráfica de ilustrar e de identificar os diferentes regimes de lubrificação que podem ser observados entre duas superfícies móveis. Os parâmetros normalmente correlacionados nessa curva são o coeficiente de atrito e o número de Hersey, que correlaciona a viscosidade do lubrificante, a velocidade do deslizamento e o carregamento normal externo, porém algumas fontes na literatura admitem apenas a velocidade de deslizamento entre as superfícies em contato, figura 1 [3].

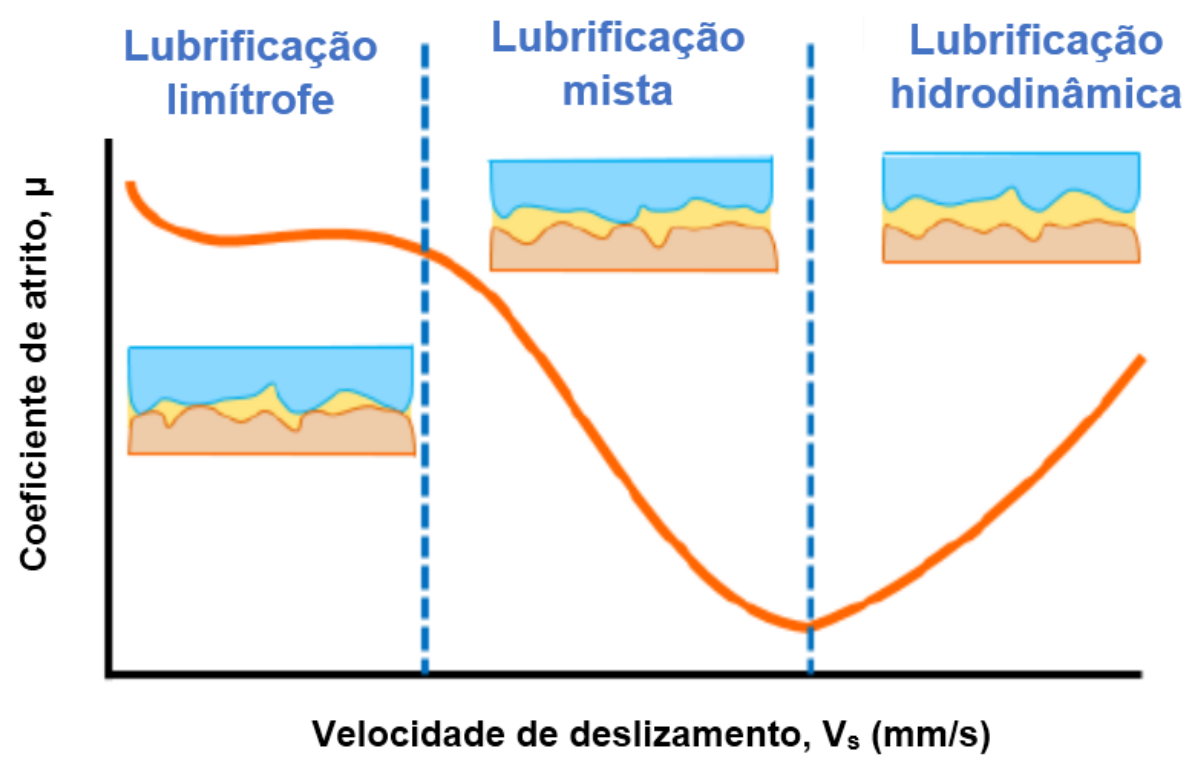

Figura 1 - Curva de Stribeck e regimes de lubrificação. (Adaptado de: Lubricants additives - Chemistry and applications)

Os aditivos modificadores de atrito atuam especialmente no regime de lubrificação limítrofe, formando um filme molecular protetivo na interface de contato devido à interação entre moléculas dos aditivos e as superfícies, de maneira a alterar o coeficiente de atrito (ou coeficiente de fricção). O regime de lubrificação limítrofe é caracterizado pela ausência de filme lubrificante espesso entre as superfícies, que ficam separadas entre si apenas pela presença de um tribofilme de dimensão molecular aderida nas interfaces [4]. O estudo da interação entre duas superfícies movendo-se entre si e todas as interações provocadas por este movimento é definido como Tribologia [5]. 
Baseado nestes principais pontos, o objetivo deste trabalho foi estudar e avaliar o comportamento tribológico de aditivos do tipo modificadores de atrito de naturezas químicas distintas e comparar seus comportamentos quando misturados em três óleos básicos selecionados, avaliando-se o efeito da sinergia entre estes insumos por meio dos resultados do CoF (coeficiente (s) de atrito) no das amostras preparadas no regime de lubrificação limítrofe.

\section{METODOLOGIA}

Neste trabalho foi utilizado o equipamento DHR-2 da fabricante TA Instruments com o módulo de tribologia, empregando-se a geometria de bola em três bolas (four ball) de aço inoxidável com dureza de 64-66 Rockwell C e grau de acabamento de superfície de $25 \mathrm{EP}$. O equipamento e a geometria utilizados são apresentados na Figura 2.
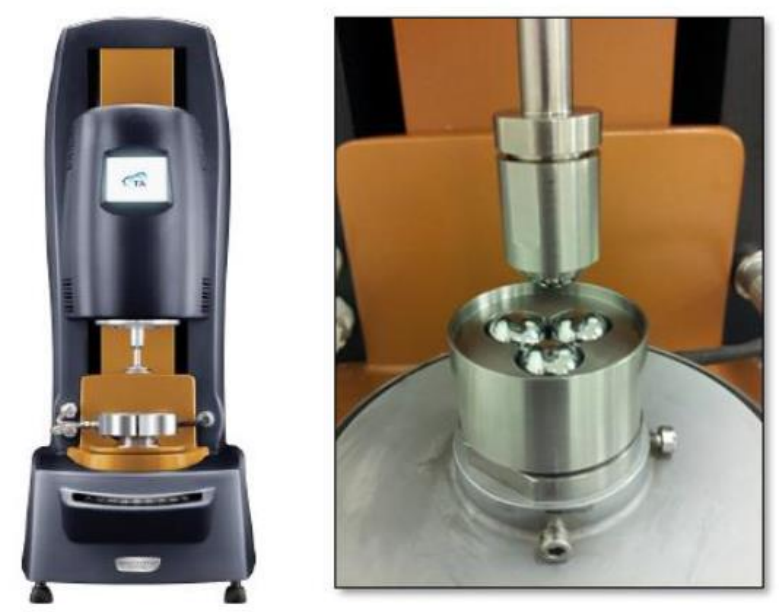

Figura 2 - Tribômetro utilizado e detalhe da configuração adotada para realização dos testes.

A tabela 1 apresenta os tipos de aditivos modificadores de atrito e os óleos básicos de diferentes origens utilizados para preparar as amostras testadas:

Tabela 1 - Aditivos e básicos selecionados para o estudo.

\begin{tabular}{|c|c|}
\hline Insumo & Natureza química \\
\hline Básico A & Óleo sintético Grupo IV \\
\hline Básico B & Óleo mineral Grupo II+ \\
\hline Básico C & Óleo origem renovável Grupo III+ \\
\hline Aditivo 1 & Complexo organo-molibdênio \\
\hline Aditivo 2 & Base polimérica \\
\hline Aditivo 3 & Base éster \\
\hline
\end{tabular}


Foram comparadas uma base sintética (Básico A), uma base mineral (Básico B) e uma base de origem renovável (Básico C), todas com a mesma viscosidade cinemática a $100{ }^{\circ} \mathrm{C}\left(4 \mathrm{~mm}^{2} / \mathrm{s}\right)$ para que o trabalho comparativo não sofra influência de viscosidade, além disso, esta viscosidade é comumente utilizada para formulação de um óleo lubrificante automotivo sintético de alta performance. Todos os aditivos foram adicionados aos básicos na mesma taxa de tratamento, 0,5\% em massa. Também foram analisadas as amostras dos básicos puros, que neste trabalho serão consideradas as amostras "branco" para efeito de comparação. Para análise das amostras, foram definidos os parâmetros de análise conforme listado a seguir:

$\checkmark$ Carga de 10N;

$\checkmark$ Tempo de ensaio: 600s

$\checkmark$ Velocidade: 0,0 a $300 \mathrm{rad} / \mathrm{s}$

$\checkmark 4,5 \mathrm{~mL}$ de amostra;

$\checkmark$ Geometria do tribômetro: bola em três bolas;

$\checkmark$ Temperatura do ensaio: $25^{\circ} \mathrm{C}$;

As medições foram realizadas em duplicata, considerando um desvio padrão calculado de 0,001 .

É importante ressaltar que o valor do coeficiente de atrito medido poderá ser influenciado de acordo com as variações na carga do teste, temperatura e material das geometrias avaliadas, as quais irão interferir na rugosidade das superfícies.

\section{RESULTADOS E DISCUSSÃO}

As curvas de Stribeck geradas para cada óleo básico e para as combinações desses com os diferentes aditivos selecionados forneceram o valor médio dos coeficientes de atrito dentro do regime de lubrificação limítrofe. Na tabela 2 estão relacionados esses resultados: 
Tabela 2 - Resultados dos coeficientes de atrito médio das amostras testadas

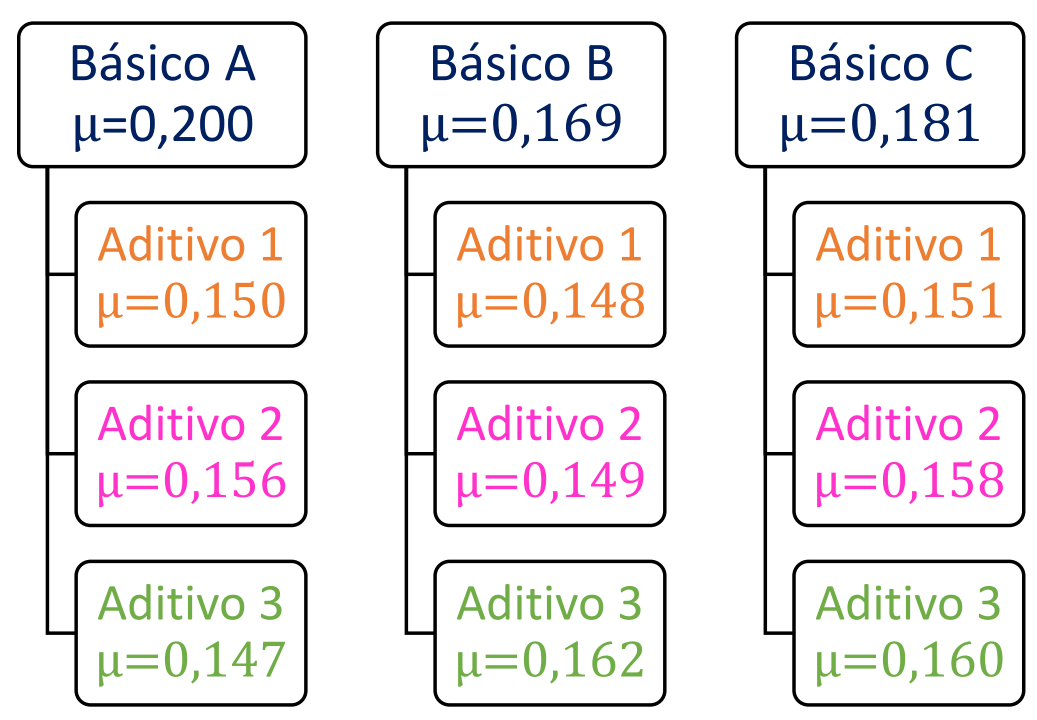

Os valores médios dos coeficientes de atrito dos óleos básicos foram considerados o ponto de partida para a avaliação das diferentes combinações entre os básicos e aditivos selecionados. Dessa forma, por meio dos resultados apresentados na Tabela 2, é possível observar que esse "ponto de partida" irá variar, pois o Básico B (Óleo mineral Grupo Il+) possui o menor coeficiente de atrito, seguido do Básico C (Óleo origem renovável Grupo III+) e do Básico A (Óleo sintético Grupo IV). Esta variação é uma característica relacionada ao processo de obtenção de cada óleo básico.

De forma generalizada, é possível observar que a adição dos aditivos modificadores de atrito aos diferentes óleos básicos, resultou em uma queda do coeficiente de atrito médio no regime de lubrificação observado, independente dos seus coeficientes de atrito iniciais. Dentre os aditivos adicionados ao óleo básico $\mathrm{A}$, o aditivo 3 apresentou o menor valor de coeficiente de atrito médio, seguido do aditivo 1 e do aditivo 2. De forma diferente, o óleo básico $B$, com a adição do aditivo 1 apresentou o menor valor do coeficiente de atrito médio, seguido do aditivo 2 e do aditivo 3 . E de maneira semelhante ao básico $B$, no óleo básico $\mathrm{C}$, a adição do aditivo 1 também apresentou o menor valor de coeficiente de atrito médio, seguido do aditivo 2 e do aditivo 3. Estes resultados demonstram a importância de se levar em conta a interação óleo básico/aditivo modificador de atrito. 
O comportamento das diferentes misturas pode ser visualizado de forma gráfica através das curvas de Stribeck a seguir, figuras 3 a 5 .

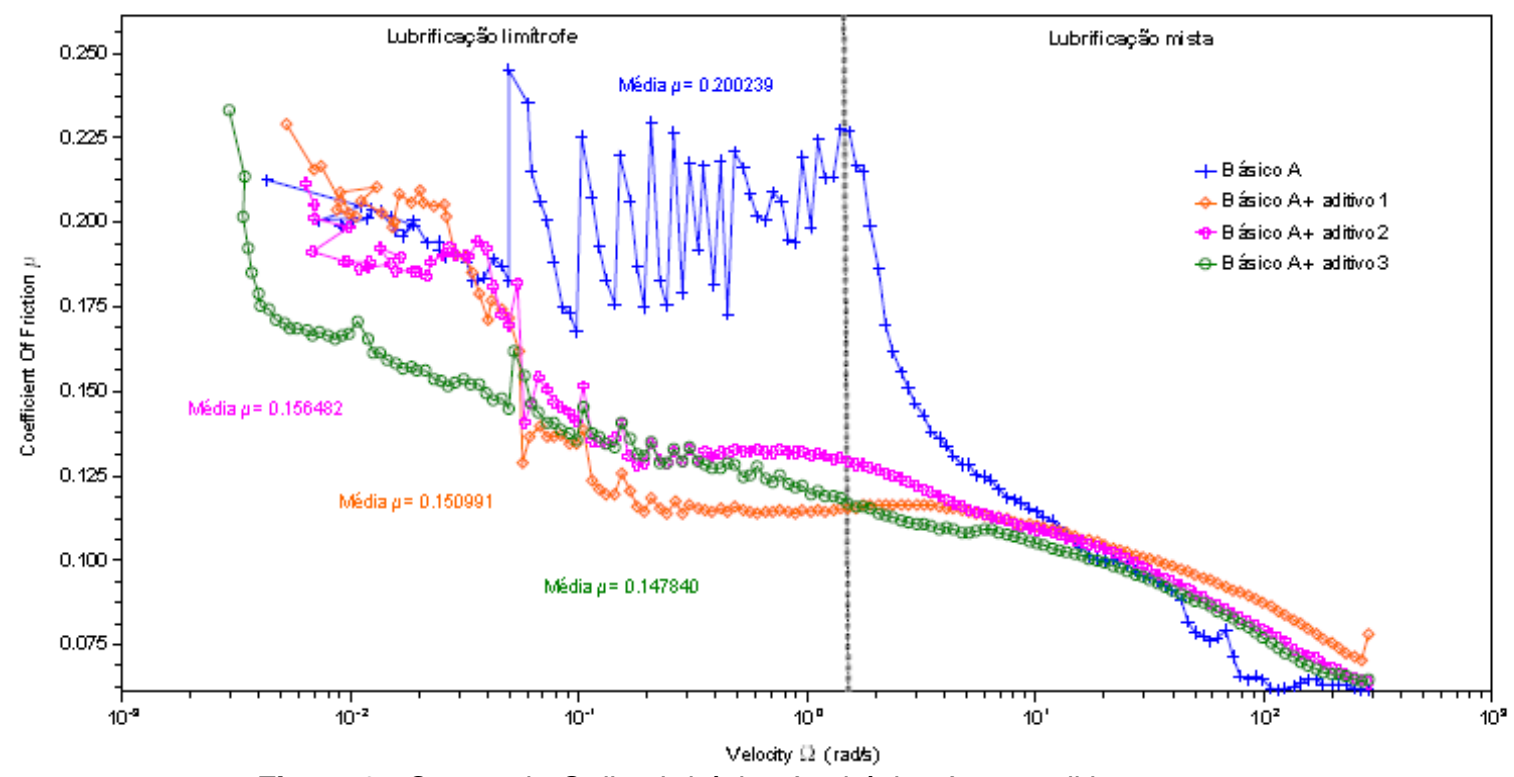

Figura 3 - Curvas de Stribeck: básico A e básico A com aditivos 1, 2 e 3.

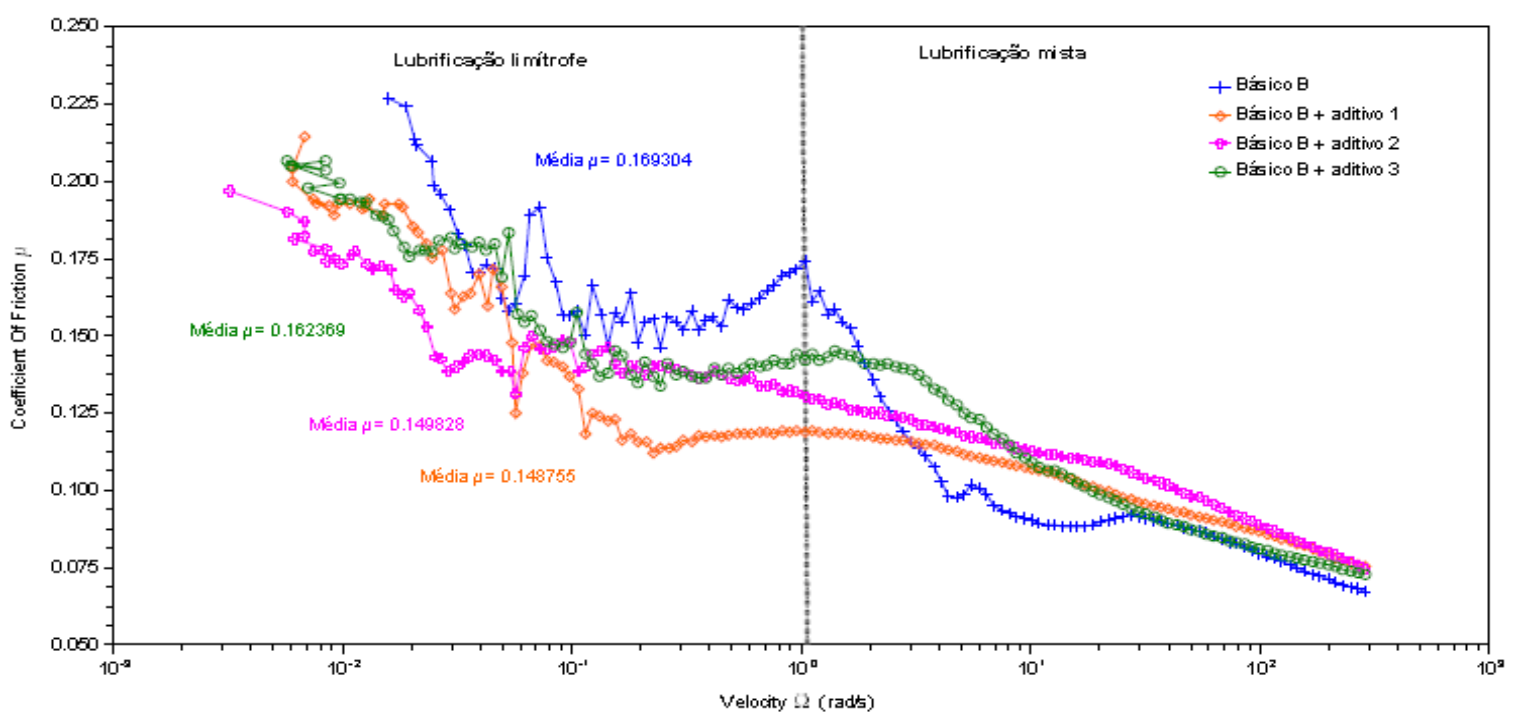

Figura 4 - Curvas de Stribeck: Básico B e Básico B com aditivos 1, 2 e 3. 


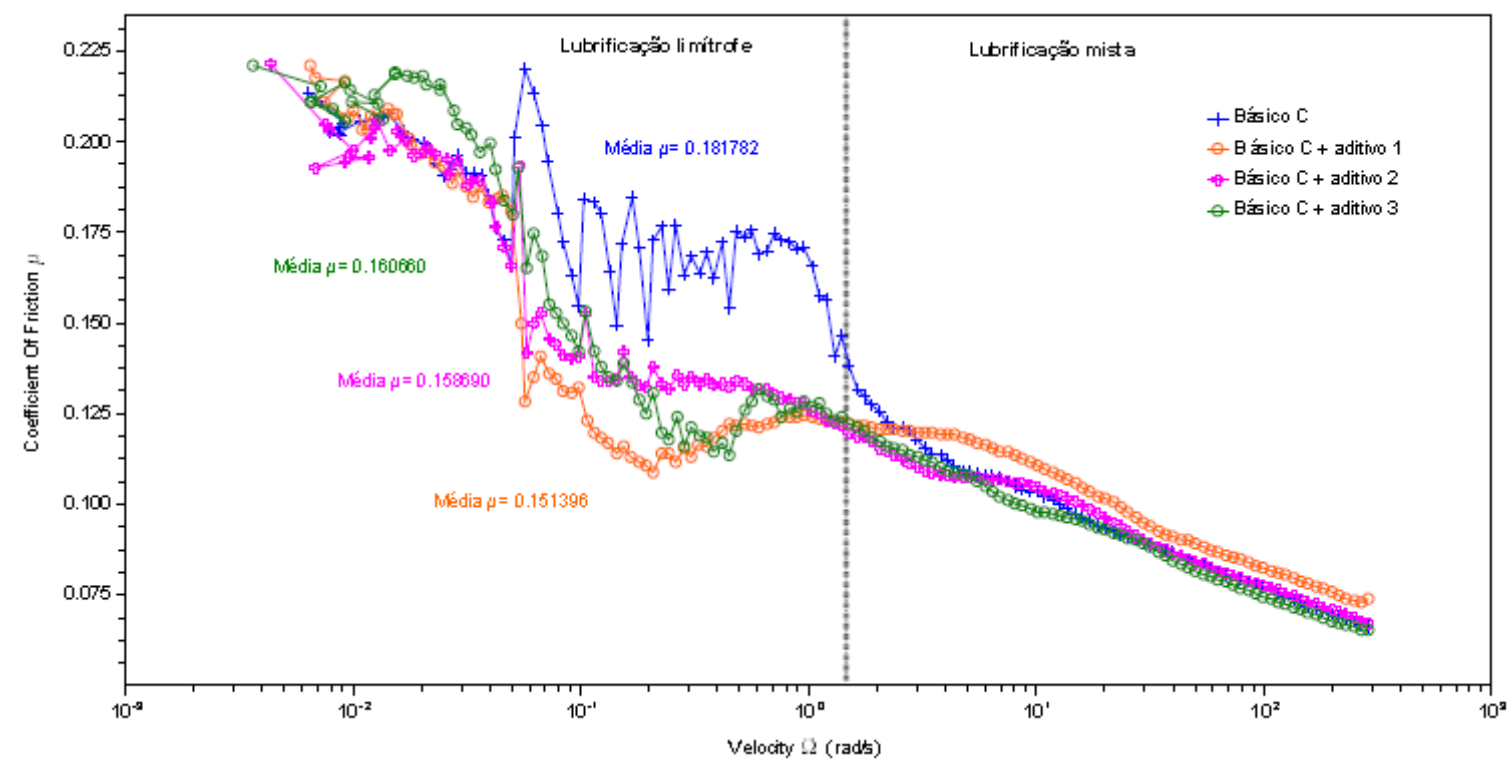

Figura 5 - Curvas de Stribeck: Básico C e Básico C com aditivos 1, 2 e 3.

Em todas as curvas de Stribeck obtidas durante a realização deste trabalho, foi observado certo "ruído" no início do teste. Isto acontece pois no regime de lubrificação limítrofe (início do teste) as rugosidades presentes na superfície metálica tem maior contribuição para o coeficiente de atrito. Os dados das curvas tendem a ser mais "suaves" e bem desenvolvidos conforme a velocidade do ensaio aumenta, uma vez que o lubrificante está contribuindo mais para o sinal gerado no equipamento (traduzido na curva como o coeficiente de atrito).

As Curvas de Stribeck apresentadas na figura 3, confirmam que houve queda do CoF para todos os aditivos testados no básico $\mathrm{A}$ com relação ao valor de CoF obtido para este básico puro. Considerando o percentual de queda, destaca-se o aditivo 3 , com $26,2 \%$, seguido do aditivo 1 , com $24,6 \%$ e do aditivo 2 , com $21,9 \%$, caracterizando a sinergia dessas misturas nessa mesma ordem. Segundo Rudnick [1], básicos sintéticos altamente saturados são muito apolares e geralmente são misturados a ésteres polares para melhorar a sua solubilidade. Isto corrobora que o aditivo 3, que é predominantemente polar, além de não sofrer interferência do óleo básico no processo de adsorção na superfície metálica, tem seu desempenho de adsorção ainda melhor.

As Curvas de Stribeck apresentadas na figura 4, novamente confirmam que houve queda do CoF para todos os aditivos testados no Básico B com relação ao valor de CoF obtido para este básico puro. O maior percentual de queda evidenciado foi de $12,1 \%$ quando adicionado o aditivo 1 ao básico $B$. Considerando que não existe problemas de solubilidade deste básico com outros insumos, como ocorre com o básico $\mathrm{A}$, era de se esperar que o aditivo 1, que é o mais polar entre os aditivos apresentasse melhor sinergia dentre os mesmos. O aditivo 2 apresentou uma redução de $11,5 \%$, seguido do aditivo 3, com 4,1 $\%$, inferindo que dependendo da polaridade dos aditivos FM (friction modifiers), 
os mecanismos de ação podem ser diferentes, pois aditivos FM do tipo orgânicos são uma mistura de moléculas polar e não-polar.

As Curvas de Stribeck apresentadas na figura 5, também confirmam que houve queda do CoF para todos os aditivos testados no Básico $\mathrm{C}$ com relação ao valor de CoF obtido para este básico puro. Considerando o percentual de queda, destaca-se o aditivo 1, com 16,7 \%, seguido do aditivo 2 , com 12,7\% e do aditivo 3, com 11,6\%, caracterizando a sinergia dessas misturas nessa mesma ordem. Neste caso, mais uma vez é possível perceber que o Aditivo 1, altamente polar, apresentou a melhor sinergia quando comparado aos aditivos orgânicos 2 e 3 que se comportaram de maneira semelhante quando adicionados no Básico $B$, sofrendo influência das suas moléculas polares e nãopolares.

\section{CONCLUSÕES}

Com base nos valores dos coeficientes de atrito médio e nas curvas de Stribeck obtidas para as amostras estudadas, é possível concluir que o aditivo 3 misturado ao básico $\mathrm{A}$ apresentou sinergia superior comparado aos demais aditivos quando misturados nesse mesmo básico, enquanto que o aditivo 1 quando misturado tanto ao básico $\mathrm{B}$ quanto ao básico $\mathrm{C}$ foi sinergicamente superior aos aditivos 2 e 3 nesta mesma condição. Assim, ficou claro nesse estudo que o efeito sinérgico entre aditivos modificadores de atrito e óleos básicos na formulação de um óleo lubrificante é influenciado pela natureza química desses insumos, podendo contribuir de forma variada na redução de atrito entre duas superfícies metálicas móveis em contato.

Além do estudo específico, com este trabalho, é possível dizer que o desempenho de um óleo lubrificante pode ser melhorado e ir além de suas especificações mínimas por meio da verificação da sinergia entres os todos insumos utilizados em sua formulação. Dessa forma, estudos avaliando a interação entre aditivos modificadores de atrito e outros aditivos, por exemplo, aditivos antidesgaste e de extrema pressão (EP/AW), os quais também atuam na superfície metálica e podem competir com aditivos modificadores de atrito devem ser considerados quando a utilização dos mesmos for necessária em uma mesma formulação. E, por fim, pode-se dizer também que os testes tribológicos destacam-se como uma excelente ferramenta para estudos comparativos. 


\section{REFERÊNCIAS}

[1] RUDNICK, Leslie R.; Lubricants additives - Chemistry and application, 2nd edition, CRC Press, 2009.

[2] McCARTHY, Shawn A,C.L.S., O.M.A. (2014). The future of heavy-duty diesel engine oils. Tribology \& Lubrication Technology, 70(10) 70(10). p. 3840; 42-44; 46-48; 50.

[3] JACOBSON, B.; The Stribeck memorial lecture. Trybology International, Oxford, v. 36, n. 11, p. 781-789, 2003.

[4] CARRETEIRO, R. P.; BELMIRO, P. N. A. Lubrificantes e Lubrificação Industrial. Editora Interciência, 2006, p.115-129.

[5] BRUNETTI, FRANCO; Motores de Combustão Interna - Volume 2. Editora Edgar Blucher, 2009, p. 343-364. 